\title{
Social Networks and Social Interaction among People with Psychiatric Disabilities-Comparison of Users of Day Centres and Clubhouses
}

\author{
Jenny Hultqvist $^{1}$, Urban Markström ${ }^{2}$, Carina Tjörnstrand ${ }^{1} \&$ Mona Eklund ${ }^{1}$ \\ ${ }^{1}$ Department of Health Sciences, Occupational Therapy and Occupational Science, Lund University, Lund, \\ Sweden \\ ${ }^{2}$ Department of Social Work, Umeå University, Umeå, Sweden \\ Correspondence: Jenny Hultqvist. Department of Health Sciences, Occupational Therapy and Occupational \\ Science, Lund University, P.O. Box 157, 22100 Lund, Sweden. Tel: 46-462-221-950. E-mail: \\ jenny.hultqvist@med.lu.se
}

Received: August 25, 2016 Accepted: October 28, 2016 Online Published: November 22, 2016

doi:10.5539/gjhs.v9n6p107 URL: http://dx.doi.org/10.5539/gjhs.v9n6p107

\begin{abstract}
Objective: The aim of the study was to compare users of community-based mental health day centres (DCs) and clubhouses in Sweden regarding reported social networks and social interaction and the stability of these over time. A further aim was to investigate social network predictors both cross-sectionally and longitudinally.
\end{abstract}

Methods: People regularly attending DCs $(n=128)$ or clubhouses $(n=57)$ completed questionnaires about social network and social interaction (social engagement and social functioning), self-esteem and socio-demographics at baseline and a nine-month follow-up.

Results: Perceived social engagement and social functioning did not differ between the groups and remained stable over time. Fewer in the DC reported having a close friend but there was no difference regarding having recently (the past week) seen a friend. When naming "someone with whom you can share your innermost thoughts and feelings", the DC group named more professional contacts, fewer friends and more often "nobody" compared to the clubhouse group. Finally, on both occasions the DC group scored significantly lower on size of the social network compared to the clubhouse users. Self-esteem and having recently seen a friend could predict size of the social network in the cross-sectional perspective. Strong indicators of belonging to the group with a larger social network at follow-up were being a woman, attending a clubhouse programme and having scored high on social network at baseline.

Conclusion and Implication for Practice: Having friends and strengthening one's self-esteem may be essential factors for the social network of people with psychiatric disabilities in a short-term perspective. Visiting clubhouses seems advantageous in a longer-term perspective.

Keywords: community mental health services, psychosocial rehabilitation, mental health recovery

\section{Introduction}

Severe and persistent mental illness (SMI) can cause a psychiatric disability, which can be defined as a significant interference with the individual's performance of major life activities and participation in everyday life and is sustained over time (Psykiatrisamordningen, 2006). It is generally acknowledged that social networks play an important role in the maintenance of psychological well-being (Kawachi \& Berkman, 2001) and in the recovery from mental illness (Onken, Craig, Ridgway, Ralph, \& Cook, 2007). Providing opportunities for social interaction and networking is thus an important component of community mental health services (Anthony \& Mizock, 2014; Elstad, 2014). Community-based day centre (DC) services form the most common psychosocial rehabilitation alternative for people with psychiatric disabilities in Sweden. Clubhouses constitute another community-based approach to psychosocial rehabilitation and, like DCs, provide opportunities for meaningful daily occupations (Norman, 2006; Tjörnstrand, Bejerholm, \& Eklund, 2011). Both approaches have been found to facilitate social interaction (Bejerholm \& Eklund, 2004; Carolan, Onaga, Pernice-Duca, \& Jimenez, 2011) and participation has been described by both groups of users as creating feelings of inclusion and belonging (Carolan et al., 2011; Tjornstrand, Bejerholm, \& Eklund, 2013a). Ascertaining whether one approach to psychosocial rehabilitation is better than others in terms of promoting social interaction generates valuable knowledge; successful programmes 
can inspire less successful ones. Participants in consumer-run community mental health programmes have reported larger and more diverse social networks as opposed to users of DCs and day hospitals (Catty, Goddard, White, \& Burns, 2005; Hardiman \& Segal, 2003). Although clubhouses are not consumer-run they are strongly consumer-centred (Bellamy, Garvin, MacFarlane, Mowbray, Mowbray, \& Holter, 2006). No research appears to have explored if day centres and clubhouses differ in terms of opportunities for social interaction and social support as perceived by the users and this study addresses this knowledge gap.

The term social network refers to a set of individuals and the patterns of relationships between them (Wasserman \& Faust, 1994). Social interaction and support are two of the processes that may take place within the social network (Berkman \& Glass, 2000). Social interaction and support and the development of meaningful personal relationships form important facets of personal recovery, which has been described as an individual process of learning to manage one's illness and pursuing a meaningful life in the community (Anthony, 1993; Noordsy, Torrey, Mueser, Mead, O'Keefe, \& Fox, 2002; Onken et al., 2007). Townly et al. (2013) found that although casual, routine interaction with community members (termed distal support) could predict recovery and community integration, the more traditional social network support (e.g. family, friends, staff) was more influential in these respects. Access to enabling social environments such as those available in DC and clubhouses can, through the long-term support they offer, provide a safety net from which the users can benefit in their recovery process (Tanaka, Craig, \& Davidson, 2015). Several researchers argue, however, that there is a risk in relying on relationships tied to programmes and that the programmes should facilitate support systems in the community (Bonavigo, Sandhu, Pascolo-Fabrici, \& Priebe, 2016). Nonetheless, other research has concluded that dependence on services also has positive effects such as social contacts and rehabilitative activities in a safe environment (Bryant, Craik, \& McKay, 2010). Since social networks and social support have repeatedly shown to be associated with recovery (Corrigan \& Phelan, 2004; Hendryx, Green, \& Perrin, 2009; Kawachi \& Berkman, 2001), it is thus important to investigate whether either of the two contexts is better suited to provide this support. Increased knowledge in this respect can form an important basis for the planning of psychosocial rehabilitation and support within community mental health services.

House (1981) proposed that social support could be divided into four subtypes: emotional (e.g. caring and understanding), instrumental (e.g. practical help and assistance), appraisal (e.g. help in decision-making) and informational (e.g. provision of information). Individuals with psychiatric disabilities may have impaired social functioning (Bellack, 2004), which hampers the ability to establish and maintain social relationships and networks. The social networks of people with psychiatric disabilities commonly decline over time and become less capable of providing social support (Tracy \& Biegel, 2006). Small or restricted social networks, and dissatisfaction with the social network, have been associated with a poor quality of life (Bengtsson-Tops \& Hansson, 2001) and increased risk of psychiatric disorders (Hawkley \& Cacioppo, 2010). Conversely, larger networks, more social contacts and better network satisfaction have been associated with fewer psychiatric symptoms and greater recovery (Corrigan \& Phelan, 2004).

Several factors have shown to be associated with the social networks of people with psychiatric disabilities. A higher education level (Goldberg, Rollins, \& Lehman, 2003), higher age, living in a house compared to a flat (Eklund \& Hansson, 2007), higher scores on self-esteem and quality of life (Bengtsson-Tops \& Hansson, 2001) and fewer psychiatric symptoms (Goldberg et al., 2003; Sörgaard et al., 2001) have all shown a positive association with larger network size. Furthermore, being female, living in an urban area and better psychosocial functioning has predicted a larger social network and more emotional relations (Sörgaard et al., 2001).

\subsection{Day Centres and Clubhouse}

Terms such as day centres, day care, community day treatment centres or mental health centres are used inconsistently in research, but generally denote community mental health services that offer a range of everyday activities, socialization and ongoing support (Bryant, Craik, \& McKay, 2005; Elstad, 2014; Yurkovich, Smyer, \& Dean, 1999). Day centre seems to be the most commonly used term (Catty, Burns, Comas, \& Poole, 2008; Nilsson, Argentzell, Sandlund, Leufstadius, \& Eklund, 2011), and such centres are run by the municipal authorities in Sweden. They have been described as mainly consisting of two types: meeting place-oriented or work-oriented (Tjörnstrand et al., 2011). Meeting-place DCs offer activities such as playing games and having a meal together. The activities in work-oriented DCs focus mainly on producing things, including preparation of food and assembly work. Some DCs combine the two orientations (Tjörnstrand et al., 2011). Common for both orientations is that they are only open during office hours. Clubhouses, on the other hand, are non-governmental, non-profit organisations that also provide evening and weekend activities (Norman, 2006). The clubhouse approach to psychosocial rehabilitation originated in the US in the 1940s and has since developed into the established 
Clubhouse Model (Raeburn, Schmied, Hungerford, \& Cleary, 2016). It has been implemented in over 300 sites internationally (McKay, Nugent, Johnsen, \& Lidz, 2016) and there are currently 12 clubhouses in Sweden (Sveriges Fontänhus Riksförbund, 2016). Personal relationships and peer support are emphasized in the model. The social structure is egalitarian and the users are referred to as members (Coniglio, Hancock, \& Ellis, 2012). Members and staff work side-by-side, sharing decision-making and the daily work such as cooking, administration and maintenance (Norman, 2006).

\subsection{Social Networks among Users of Clubhouses and Day Centres}

Several studies have explored aspects of social networks among clubhouse members (Biegel, Pernice-Duca, Chang, Chung, Min, \& D'Angelo, 2013; Carolan et al., 2011; Pernice-Duca \& Onaga, 2009; Pernice-Duca, 2008). Pernice-Duca (2008) and Beigel et al. (2013) found that although clubhouse staff and peers made up a substantial portion of the social network, family members were the most nominated source of support. A longitudinal study found that family, friends and clubhouse peers remained relatively stable sources of support, whereas clubhouse staff and other professionals were named less often over time (Pernice-Duca \& Onaga, 2009). Comparative studies addressing social aspects in the clubhouse context are scarce. Nevertheless, Hultqvist and colleagues (2016) explored organizational factors in DCs and clubhouses and found that clubhouse members scored higher than DC attendees on "characteristics of the social context", which includes feelings of inclusion and belonging and of being valued by others. Another study compared clubhouse members with participants in Assertive Community Treatment Programmes and found the experiences of social relationships and networks to be similar (Stein, Barry, Dien, Hollingsworth, \& Sweeney, 1999).

Studies concerning the social networks of users of DC are rare. Research comparing users of day centres with those attending day hospitals has shown, however, that the former reported more social interaction (Catty, Goddard, \& Burns, 2005a) and were more likely to confide in friends and neighbours than in professionals (Catty, Goddard, White, \& Burns, 2005b). A Swedish study showed that social support was mainly provided by informal caregivers, for example, family members. The DC users reported larger social networks, but did not experience better quality in their relationships than non-users with psychiatric disabilities (Argentzell, Leufstadius, \& Eklund, 2013). Furthermore, the results of a British study showed that DCs met an important need for social contacts and enhanced continuity of the users' social context (Sweeney et al., 2016).

Research comparing users of DCs and clubhouses regarding their social networks and social interaction is lacking. There is also a knowledge gap concerning factors that can predict the social network in the target group. Increased understanding of the users' perceptions of the social network and its predictors would shed light on integral factors for mental health and recovery. Previous research suggests that social networks change over time (Tracy \& Biegel, 2006). It thus seems important to also address stability over time when exploring social networks among users of DC and clubhouses and also to control for level of functioning and well-being, which have been found to be related with both qualitative and quantitative aspects of the social network (Bengtsson-Tops \& Hansson, 2001).

\section{Aims}

The overarching aim was to compare users of DCs and clubhouses regarding perceptions of their social network and social interaction. The specific aims were a) to compare the groups on social network size and social interaction, and investigate change in each group separately from baseline to a nine-month follow-up; b) to compare the groups regarding the roles of persons identified as giving the users emotional support; and c) to explore which baseline factors could predict the social network size cross-sectionally and longitudinally, taking sociodemographic factors, perceived social interaction and time attending the programme into consideration and controlling for psychosocial functioning and self-esteem.

\section{Material and Methods}

The present study employed a naturalistic, longitudinal design.

\subsection{Setting, Procedure and Selection of Participants}

The study participants ( $\mathrm{n}=185$ at baseline; $\mathrm{n}=154$ at follow up) included men and women regularly attending DCs ( $n=128$ at baseline; $n=116$ at follow up) or clubhouses ( $n=57$ at baseline, $n=37$ at follow up).

The DC attendees came from two previous projects. Firstly, four DCs located in three regions in the south of Sweden were included. These day centres were of work-oriented as well as meeting place-oriented character. The four DCs had constituted a control group in an intervention study and as such had not taken part of the intervention (Eklund, Gunnarsson, Sandlund, \& Leufstadius, 2014). The intervention entailed enriching the DC with more meaningful activities, but since these four DCs were used as controls and did not take part in the intervention they 
could be included in the present study. The data collection included a follow-up after approximately nine months, which set the follow-up interval for the current study as a whole at nine months. Secondly, six further DCs from central Sweden were included. Attendees from these DCs had taken part in a project investigating organisational change in DC services due to new Swedish legislation concerning freedom of choice in health care and social services and are described in more detail in a previous study (Eklund \& Markstrom, 2014). A double baseline measurement with a nine-month interval was performed before implementation of the reform, and those two measurements were used for the present study. The DC units were both work-oriented and meeting place-oriented. In both projects, managers of the selected DCs were contacted and informed about the study and asked whether the researchers and project assistants could visit the unit to inform attendees and staff about the study.

The study included five purposely selected clubhouses in central and southern Sweden. These were members of the Swedish National Organization for Clubhouses (Riksförbundet Sveriges Fontänhus) and Clubhouse International (ICCD). Four of the five clubhouses were accredited and one that had recently opened was not, but its director had long experience as a director of an accredited clubhouse. The directors of the selected clubhouses were contacted by the first author. After obtaining the members' approval the first author, and on two occasions a research assistant, were invited to meetings where all clubhouse members had the opportunity to attend. A follow-up was made to obtain more robust data for investigating the main aim, but also to address stability over time regarding the number of social contacts and the users' perspective on social support.

All DC attendees and clubhouse members in the selected settings were invited to participate. A minimum attendance of four hours per week was set as an inclusion criterion. Exclusion criteria were: substance abuse as the main diagnosis and co-morbidity with dementia or learning disabilities. Socio-demographic and clinical characteristics of the participants are presented in Table 1. Differences in socio-demographic factors between DC attendees and clubhouse members were investigated. The analysis showed no significant differences between the two groups regarding gender $(p=0.467)$, age $(p=0.978)$, civil status $(p=0.902)$ or education $(p=0.528)$. The analysis concerning clinical factors revealed no differences between the groups regarding self-reported diagnosis $(p=0.159)$, but there was, however, a significant difference regarding the GAF score, DC attendees being rated lower $(\mathrm{p}=0.010)$. The GAF score denotes psychological, social, and occupational functioning on a hypothetical continuum ranging from extremely good mental health $(=100)$ to extremely bad mental ill-health $(=0)$ (Vatnaland, Vatnaland, Friis, \& Opjordsmoen, 2007). For example, a score below 50 indicates lacking work capacity.

Table 1. Socio-demographic and clinical characteristics of the participants at baseline.

\begin{tabular}{|c|c|c|}
\hline Characteristics & $\mathrm{DC}(n=128)$ & Clubhouses $(n=57)$ \\
\hline Gender; male/female: $n(\%)$ & $60(47 \%) / 68(53 \%)$ & $23(41 \%) / 33(59 \%)$ \\
\hline Age: mean(min.-max.) & $48.7(23-72)$ & $48.7(28-69)$ \\
\hline Civil status; married or cohabitant/single: $n(\%)$ & $17(14 \%) / 108(86 \%)$ & $8(14 \%) / 48(86 \%)$ \\
\hline \multicolumn{3}{|l|}{ Education level: $n(\%)$} \\
\hline not completed compulsory school & $8(6 \%)$ & $1(2 \%)$ \\
\hline completed compulsory school & $35(28 \%)$ & $12(23 \%)$ \\
\hline completed sixth-form college & $61(48 \%)$ & $28(54 \%)$ \\
\hline completed undergraduate studies & $22(18 \%)$ & $11(21 \%)$ \\
\hline Have a close friend: yes/no $n(\%)$ & $100(78 \%) / 28(22 \%)$ & $52(93 \%) / 4(7 \%)$ \\
\hline Have seen a friend during the last week: yes/no $n(\%)$ & $70(57 \%) / 53(43 \%)$ & $38(68 \%) / 18(32 \%)$ \\
\hline \multicolumn{3}{|l|}{ Hours per week at DC or clubhouse: } \\
\hline \multicolumn{3}{|l|}{ mean $\left(\min ^{1}-\max \right)$} \\
\hline Baseline & $15(2-35)$ & $21(5-40)$ \\
\hline Follow-up & $15(1.5-35)$ & $21(4-40)$ \\
\hline \multicolumn{3}{|l|}{ Self-reported diagnosis: $n(\%)$} \\
\hline Psychoses $(\mathrm{F} 20)^{1}$ & $27(21 \%)$ & $8(14 \%)$ \\
\hline Mood and anxiety disorders (F30+F40) & $47(37 \%)$ & $29(51 \%)$ \\
\hline Autism/neuropsychiatric disorders (F80+F90) & $16(12 \%)$ & $5(9 \%)$ \\
\hline
\end{tabular}




\begin{tabular}{ccc}
\hline Other disorders (mostly F60 and unknown) & $38(30 \%)$ & $15(26 \%)$ \\
Global Assessment of Functioning (GAF): $\operatorname{med}($ min-max) & $47(20-85)$ & $51(30-80)$ \\
\hline
\end{tabular}

Note. Internal attrition was between 0 and 8 on the above variables. ${ }^{1)}$ One DC participant reported less than the stipulated minimum of four hours on both occasions. ${ }^{1} \mathrm{~F} 20, \mathrm{~F} 30, \mathrm{~F} 40, \mathrm{~F} 60, \mathrm{~F} 80$ and F90 are codes in the clinical cataloguing system ICD-10 (International Statistical Classification of Diseases and Related Health Problems - Tenth Revision)

\subsection{Ethical Considerations}

The participants received oral and written information. Informed consent and assurance of confidentiality and voluntariness were applied. The interviews took place in a private room at the DC or clubhouse. The data collection took approximately one hour and breaks were made if needed. The study is based on data collected from participants included between 2008 and 2014. Approval was obtained from the Regional Ethical Review Board at Lund University (Reg. no. 2008/274; Reg. no. 2009/625 and Reg. no. 2012/70).

\subsection{Data Collection}

Self- report questionnaires were used to collect the data. The first author or a project assistant collected the data at the clubhouses. Five project assistants were involved in the data collection at the DCs in central and southern Sweden. All project assistants were trained occupational therapists with experience from working with the target group and from performing data collection.

The Interview Schedule for Social Interaction. The Swedish self-report version [ISSI-SR] (43), of The Interview Schedule for Social Interaction [ISSI] (Henderson, Duncan-Jones, Byrne, \& Scott, 1980) was used in the present study. Psychometric testing has indicated good reliability and validity of the ISSI-SR when used with people with different psychiatric conditions (Eklund, Bengtsson-Tops, \& Lindstedt, 2007). The ISSI-SR comprises 30 items that form four sub-scales. Two of the sub-scales examine aspects of social interaction: Availability of Social Integration (AVSI), which addresses the amount of social contacts a person has, and Availability of Attachment (AVAT), which concerns access to close relationships. The other two address the quality or adequacy of the same. The present study used a brief scale to measure the social network; it combines five items from the AVSI sub-scale, which have shown the best psychometric properties of the ISSI-SR subscales (Eklund et al., 2007) and two items from the AVAT sub-scale. This brief scale has been proposed as adequate when using several instruments with respondents that are easily exhausted, such as people with psychiatric disabilities (A. Bengtsson-Tops, personal communication, September 1, 2009). The AVSI items concerned the role of the network member who provides emotional support. The maximum sum score of this brief scale is seven. A Cronbach alpha coefficient of 0.58 based on the current sample indicates somewhat low internal consistency but sufficient for group comparisons (Birren, Lubben, Rowe, \& Deutchman, 1991).

Profiles of Occupational Engagement in People with Severe Mental Illness: Productive Occupations (POES-P). POES-P (Tjörnstrand, Bejerholm, \& Eklund, 2013) was developed on the basis of the Profiles of Occupational Engagement in People with Schizophrenia [POES] (Ulrika Bejerholm \& Lundgren-Nilsson, 2015). It has two parts, the first being a time-use diary listing activities performed and the second a rating on the basis of the diary content. The $P$ in the POES-P denotes "productive occupations," indicating that the time-use diary as well as the assessment focuses on the hours spent in productive activities. In the present study two items from the second part of POES-P were used, selected since they address aspects of social support and interaction at the DC/clubhouse (Ulrika Bejerholm \& Lundgren-Nilsson, 2015). Item 4: I feel that I have the support I need from other people. Item 5: I think that I manage being around other people.

Self-esteem. The Rosenberg Self -Esteem scale (RSES) which was used in the present study was designed to measure a global sense of self-worth (Rosenberg, 1965). The scale consists of ten questions which in the present study were answered with yes or no by the respondent as recommended by Oliver, Huxley, Priebe, \& Kaiser (1997). The RSES has two subscales, indicating positive and negative self-esteem, and the final score, which may vary from -1 (negative) to 1 (positive), is expressed as a balance between the two. The RSES has in psychometric testing been found to have satisfactory item convergent and discriminant validity, internal consistency reliability, and to be without floor and ceiling effects (Sinclair et al., 2010) and to have good test-retest reliability (Torrey, Mueser, McHugo, \& Drake, 2000).

Socio-demographic and clinical factors. A questionnaire devised specifically for this study was used to collect socio-demographic factors such as gender, age, civil status, educational level and hours spent weekly at the day centre or clubhouse. Two questions concerned whether the participant had a close friend and had seen this friend 
during the last week or not. The participants were also asked for their self-reported diagnosis. A diagnosis made by a professional could not be obtained since no medical records were kept at the DCs or clubhouses. Based on the self-reports a specialist psychiatrist made ICD-10 diagnoses according to a previously validated procedure (Eklund \& Sandlund, 2012). The Global Assessment of Functioning [GAF] (Vatnaland et al., 2007) was used to measure psychosocial functioning. The scale ranges from 1 to 100; a higher value indicates fewer and/or less severe psychiatric symptoms and better functioning. Psychometric research has found that the GAF can be rated reliably after minimal training (Startup, Jackson, \& Bendix, 2002), and all the research assistants in the present study had received specific training and calibration for making the GAF rating.

\subsection{Data Analysis}

Prior to the statistical analyses, responses from open-ended questions from the ISSI-SR, concerning the persons from whom emotional support was perceived, were classified into five categories that are further described below. The Kruskal-Wallis' H-test was applied to investigate differences between the groups. The main parts of the quantitative data were not normally distributed and were derived from ordinal scales and non-parametric statistics were thus used. The Mann-Whitney U-test was applied to investigate differences between the DC attendees and the clubhouse members at baseline and follow-up. The Wilcoxon signed-rank test was used to explore differences over time. Differences on socio-demographic and clinical data were investigated by the Chi-square test and the independent samples $t$-test and the Kruskal Wallis' H-test. The Spearman rank correlation was employed to examine relationships between variables. Finally, two logistic regression models were performed in order to analyse which variables could explain the size of the social network. The first of these had social network at baseline as the dependent variable and the other concerned the social network situation at follow-up. Both of these were dichotomised according to a median cut to create dichotomous variables. Predictor variables showing an association of $\mathrm{p}<0.10$ were included in the regression models. Age was also dichotomized according to a median cut. This was done due to the great variation in the age variable, which if significant might otherwise make the result difficult to interpret. The data analyses were performed with the SPSS software, version 21 . The level of significance was set at $<0.05$.

\section{Results}

\subsection{Differences between Day Centres and Clubhouses}

The analysis of the social network size showed a significant difference between the groups at both baseline $(\mathrm{p}=0.026)$ and follow-up $(\mathrm{p}<0.001)$, the DC group scoring lower on both occasions.

The two groups did not differ at baseline regarding perceptions of social interaction in the programme, as measured by item $4(\mathrm{p}=0.343)$ and item $5(\mathrm{p}=0.349)$ from POES-P; nor did they differ at follow-up on these items $(\mathrm{p}=0.475$ and $\mathrm{p}=0.546$, respectively).

\subsection{Comparison over Time}

The size of the social network showed to be stable in the clubhouse group ( $\mathrm{p}=0.245)$, but to significantly decline in the DC group ( $\mathrm{p}=0.048)$. Descriptive statistics are presented in Table 2.

Table 2. Social network in day centres and in clubhouses at baseline and follow-up

\begin{tabular}{llll}
\hline Variable & $\mathrm{DC}^{1}$ & Clubhouse $^{2}$ & $\mathrm{p}$-value \\
\hline $\begin{array}{l}\text { Social network, } \\
\text { baseline: } M d \text { (min-max) }\end{array}$ & $3.3(0.0-7.0)$ & $4.0(1.0-6.0)$ & 0.026 \\
$\begin{array}{l}\text { Social network } \\
\text { follow-up: } M d \text { (min-max) }\end{array}$ & $3.0(0.0-7.0)$ & $4.0(2.0-7.0)$ & $<0.001$ \\
\hline
\end{tabular}

Note: ${ }^{1}$ Missing values $=3,{ }^{2}$ missing values $=1$.

The perception of social interaction, reflected in item 4 ( $\mathrm{p}=0.345$ for DC group and $\mathrm{p}=0.591$ for clubhouse group) and item $5(\mathrm{p}=0.740 / \mathrm{p}=0.198)$ from POES-P, was similar for both groups and showed to be stable over time.

\subsection{Comparisons Regarding Persons Providing Emotional Support}

The persons named as providing the DC attendees and clubhouse members with emotional support formed the following five different categories: no one, family (for example partner, spouse, parent, sibling, or grandparent), friend, staff at DC/clubhouse, and professional (e.g. psychologist, mental health worker, social worker, clergy). 
The analysis showed no difference between the groups $(\mathrm{p}=0.639)$ regarding the response to "Someone who would feel happy just because you are happy". There was, however, a significant difference $(\mathrm{p}=0.034)$ regarding "Someone with whom you can share your innermost thoughts and feelings". For this item the DC group nominated more professional contacts, fewer friends and more often no one at all compared to the clubhouse group. The naming of family members and DC/clubhouse staff were similar in the groups (Table 3).

There was a significant difference regarding having a close friend, where fewer in DC group reported having a close friend $(\mathrm{p}=0.015)$, whereas there was no difference between the groups regarding having seen a friend during the last week $(\mathrm{p}=0.165)$.

Table 3. The roles of persons named by DC attendees and clubhouse members as giving emotional support

\begin{tabular}{lcc}
\hline Variable & $\mathrm{DC}^{1}$ & Clubhouse $^{2}$ \\
\hline Is there someone who would feel happy just because you are happy? & & $7(12.5 \%)$ \\
\hline No one: $\mathrm{n}(\%)$ & $25(20.2 \%)$ & $24(42.9 \%)$ \\
Family: $\mathrm{n}(\%)$ & $54(43.5 \%)$ & $23(41.1 \%)$ \\
Friend: $\mathrm{n}(\%)$ & $35(28.2 \%)$ & $2(3.6 \%)$ \\
Staff at DC/clubhouse: $\mathrm{n}(\%)$ & $3(2.4 \%)$ & $0(0.0 \%)$ \\
Professional contact: $\mathrm{n}(\%)$ & $7(5.6 \%)$ & $10(17.9 \%)$ \\
\hline Is there someone with whom you can share your innermost thoughts and feelings? & $32(25.6 \%)$ & $21(37.5 \%)$ \\
\hline No one: $\mathrm{n}(\%)$ & $45(36.0 \%)$ & $19(33.9 \%)$ \\
Family: $\mathrm{n}(\%)$ & $27(21.6 \%)$ & $2(3.6 \%)$ \\
Friend: $\mathrm{n}(\%)$ & $0(0.0 \%)$ & $4(7.1 \%)$ \\
Staff at DC/clubhouse: $\mathrm{n}(\%)$ & $21(16.8 \%)$ & \\
Professional contact: $\mathrm{n}(\%)$ & & \\
\hline
\end{tabular}

${ }^{1}$ Missing values $=3,{ }^{2}$ missing values $=1$.

\subsection{Multivariate Analysis}

Table 4. Correlations between baseline variables and social network size at baseline and follow-up

\begin{tabular}{|c|c|c|c|c|}
\hline \multirow{2}{*}{ Variables (baseline) } & \multicolumn{2}{|c|}{ Social network size at baseline } & \multicolumn{2}{|c|}{ Social network size at follow-up } \\
\hline & $r$ & p-value & $r$ & p-value \\
\hline Self esteem & 0.209 & 0.005 & 0.165 & 0.041 \\
\hline Having a close friend & -0.197 & 0.008 & -0.142 & 0.081 \\
\hline Having seen friend during the last week & -0.266 & $<0.001$ & & ns \\
\hline Psychosocial functioning & 0.228 & 0.002 & 0.268 & 0.001 \\
\hline Gender & 0.140 & 0.059 & 0.144 & 0.057 \\
\hline Age & 0.132 & 0.077 & & ns \\
\hline Civil status & & ns & -0.136 & 0.096 \\
\hline Group (DC/clubhouse) & -0.166 & 0.026 & -0.327 & $<0.001$ \\
\hline Social network size at baseline & & & 0.579 & $<0.001$ \\
\hline
\end{tabular}

At baseline gender, age, psychosocial functioning, having a friend, seen a friend during the last week, self-esteem, and "group" (DC attendee/clubhouse member) showed an association of $\mathrm{p}<0.10$ with size of the social network (Table 4). These formed the independent variables in the logistic regression model with the social network at baseline as the dependent variable. Two of the variables could predict the social network in this cross-sectional perspective: self-esteem and having seen a friend during the last week (Table 5). The model was supported by a non-significant Hosmer-Lemeshow test $(\mathrm{p}=0.993)$ and explained $24.7 \%$ of the variance in the dependent variable. The odds ratios indicated that a high level of self-esteem was associated with a close to threefold chance, and 
having seen a friend a fourfold chance, of belonging to the group with a larger network (Table 5).

Table 5. Results from logistic regression analyses with baseline social network size as the dependent variable

\begin{tabular}{llll}
\hline Variable & Odds ratio & $95 \%$ C.I. & p-value \\
\hline Self-esteem & 2.991 & $1.554-5.754$ & 0.002 \\
Having seen friend & 4.019 & $1.715-9.415$ & 0.001 \\
\hline
\end{tabular}

The second model included baseline self-esteem, having a close friend, psychosocial functioning, gender, group, civil status and baseline social network (Table 4). Three of the baseline variables could predict social network size at follow-up: gender, group (DC/clubhouse) and the social network size at baseline (Table 5). The model was supported by a Hosmer-Lemeshow test with $\mathrm{p}>0.05(0.434)$ and explained $38.6 \%$ of the variance in the dependent variable. Strong indicators of belonging to the group with a larger social network were being a woman and attending a clubhouse programme, both of which were associated with close to a threefold chance of belonging to the group with a larger social network. Another strong indicator for belonging to the group with larger social network was belonging to the group with larger social network at baseline as indicated by an odds ratio of 2.5 (Table 6).

Table 6. Results from logistic regression analyses with follow-up social network size as the dependent variable

\begin{tabular}{llll}
\hline Variable & Odds ratio & $95 \%$ C.I. & p-value \\
\hline Gender (women/men) & 2.786 & $1.130-6.871$ & 0.026 \\
Group (DC/clubhouse) & 2.741 & $1.036-7.250$ & 0.042 \\
High social network at baseline vs low & 2.523 & $1.725-3.690$ & $<0.001$ \\
\hline
\end{tabular}

\section{Discussion}

The results showed that DC attendees experienced significantly smaller social networks compared to clubhouse members. Several factors may explain this, such as the fact that the DC group was rated lower on psychosocial functioning, which has shown to be a predictor of smaller social networks in previous research (Sörgaard et al., 2001). Although psychosocial functioning showed a bivariate association with social network in the present study it was not significant in any of the regression analyses, which indicates that other predictors were more important. The main explanation may instead be that participants in consumer-run community mental health programmes tend to report larger and more diverse social networks as opposed to users of DCs and day hospitals (Catty et al., 2005a; Hardiman \& Segal, 2003). Although the clubhouses are not consumer-run they are strongly consumer-centred (Bellamy at al., 2006) and this approach and the emphasis on peer support probably facilitate the making of friends and strengthen one's network. A consumer-centred approach and peer support may, however, also be a feature to some extent in the DC services. Since these aspects were not addressed in the present study, no firm conclusion can be made as to causes behind the identified difference.

The social network size was stable over time in the clubhouse group, while there was a significant decline in the DC group. The reason for this is unknown, but it is possible that worries regarding the imminent free-choice reform in one of the DC samples may have influenced their ratings at the follow-up. It should be noted, however, that although network size has been found to be important for recovery (Corrigan \& Phelan, 2004; Hendryx et al., 2009), a larger size network may not automatically increase the quality of, or satisfaction with; the social network and social support (Argentzell et al., 2013). Brunt and Hansson (2002) found that low scores on availability of social integration were accompanied by higher scores on satisfaction with social integration, indicating that small networks can provide the support needed and thus be perceived as adequate.

The result also showed that the groups did not differ regarding perceptions of social interaction in the programmes; nor did any of the groups' ratings change over time. This indicates that both approaches were equally suited for providing support in this respect. DC services are generally more densely staffed compared to clubhouses, where the aim is to have a low staff-to-member ratio and an emphasis on peer support. The balance between staff managing and peer support may play a role in how the users perceive social interaction and relationships. Such nuances may be obscured in a quantitative paper like the present one. Further studies could preferably explore this 
balance, particularly in the DC context where this is very rarely studied; also the reciprocity in users' relations with peers needs to be explored since previous research has found this important for the personal recovery process (Davidson, Chinman, Sells, \& Rowe, 2006; Topor, Borg, Di Girolamo, \& Davidson, 2009).

The groups did not differ, in terms of perceived emotional support, regarding the roles of the persons named as "Someone who would feel happy just because you are happy". While regarding "Someone with whom you can share your innermost thoughts and feelings", there was a significant difference indicating that the DC attendees relied to a greater extent on professional contacts. This might be due to more frequent professional contacts, although this does not have any support in previous research in the DC context, indicating low-frequency use of psychiatric services (Eklund \& Sandlund, 2012). Furthermore, as compared to the clubhouse members, the DC attendees mentioned more seldom a friend as someone with whom they could share their innermost thoughts and feelings. This is in line with our finding that the DC group to a lesser extent had someone they saw as a close friend compared to the clubhouse group. This could be due to their lower level of psychosocial functioning (Sörgaard et al., 2001), but could also be a result of the organisation within the programmes. If this is the case, the DC services were less successful in supporting the establishment of informal social relationships, and thus less successful in applying an important principle of personal recovery. Research among people with psychosis has shown that those whose social networks consisted primarily of friends and other non-relatives reported better recovery and better social and occupational functioning compared to people whose networks were composed primarily of relatives (Erickson, Beiser, \& Iacono, 1998; Sörgaard et al., 2001). This suggests that opportunities for people with psychiatric disabilities to add non-relatives to their social network would be important and strengthen their chances for personal recovery. Such opportunities may be created by organizing psychosocial rehabilitation in such a way that it enhances access to community-based social arenas and contacts with the surrounding society.

Finally, the result of the first multivariate analysis showed that having seen a friend during the last week and higher self-esteem were strong indicators for belonging to the group with a larger social network at baseline. Having seen a friend as an indicator appears to be logical. The result regarding self-esteem is supported by previous research on people with psychiatric disabilities, showing a positive association between their self-esteem and the size of their social network (Goldberg et al., 2003). Where the follow-up perspective is concerned, belonging to the group with a larger social network was predicted by being a woman, participating in a clubhouse programme and belonging to the group with a larger social network at baseline. Females have in previous studies been reported to have larger social networks (Bengtsson-Tops \& Hansson, 2001; Sörgaard et al., 2001), but there are also studies reporting no differences between women and men (Goldberg et al., 2003). Baseline social network was smaller in the DC group compared to the clubhouse group and declined further over time; it thus appears logical that belonging to the clubhouse group was associated with a larger social network at follow-up. The finding that belonging to the group with a larger social network at baseline increased the likelihood of belonging to the high group at follow-up also appears to be logical. Despite the slightly lower odds ratio, the social network at baseline was highly significant, more so than gender and group. The findings indicate that all three factors, gender, type of service and baseline social network, played important roles for social network at follow-up.

\subsection{Methodological Considerations}

The design of this study, with two measurement points, served to increase the internal validity by providing both cross-sectional and longitudinal findings. Although this is a strength of the study, there are also some weaknesses that need to be mentioned. The internal consistency of the scale for estimating social network size was at the lower end of what is acceptable for group comparisons. This means that findings with p-values just under or above the level of significance should be interpreted with caution, such as the decline in social network size in the DC group from baseline to follow-up. The difference between the groups at the follow-up was clearly significant, however, as were the findings from the regression analyses.

No information was gathered regarding the participants' length of stay in the DC or clubhouse. Since we have no information to confirm whether the groups differed regarding length of stay in the respective programmes we cannot make any assumptions about its impact on social network. The results of a previous study in a DC context rendered some evidence that longer duration of using the services was associated with a larger social network (Catty et al., 2005b). A study in the clubhouse context found, however, that neither length of membership nor weekly participation was associated with social network size (Pernice-Duca, 2008). Further research is therefore needed to investigate whether length and frequency of attendance play a role for the size of social networks among user of DCs and clubhouses.

The number of non-participants could not exactly be estimated thus making the generalizability of this study an 
issue. The external validity would be limited if the DC attendees and clubhouse members who were most affected by their psychiatric disability chose not to participate. Moreover, no medical records are kept in DC or clubhouses in Sweden and we thus had to rely on self-reported diagnoses. Previous research has shown, however, that both DC attendees and clubhouse members represent a variety of mental disorders that cause psychiatric disability (Eklund \& Sandlund, 2012; Mowbray, Woodward, Holter, MacFarlane, \& Bybee, 2009) and prior research gives some support to the validity of self-reported diagnoses (Eklund \& Sandlund, 2012).

\section{Conclusion}

It is a challenge for mental health services like DCs and clubhouses to assist people with psychiatric disabilities in maintaining their existing relationships and support them in creating new ones, within and outside of the programmes. The conclusion from the current study is that having friends and strengthening one's self-esteem may be essential factors in a short-term perspective. Thus, providing opportunities for people with psychiatric disabilities to add non-relatives to their social network is important to strengthen their chances for personal recovery. Such opportunities may be created by organizing psychosocial rehabilitation in such a way that it enhances access to community-based social arenas and contacts with the surrounding society. Furthermore it appears important for DCs and clubhouses to ensure that the activities in the programmes afford the users to use their competencies and abilities and that the activities are at an appropriate level of engagement when striving to support the strengthening of self-esteem. Visiting clubhouses appear to be advantageous in a longer-term perspective. Female gender also showed to be beneficial, and studying women's way of socialising and encouraging men to follow their examples might be advantageous for the latter. Furthermore the current findings in relation to previous research implicate that developing strategies to increase peer support as well as striving to improve an environment that further supports the establishment of informal social relationships appears warranted in the DC services. Although this study contributed some new knowledge, further research should address which circumstances are associated with maintaining stability in one's social network, and preferably increasing both its size and adequacy.

\section{Acknowledgements}

The authors thank the study participants and the Swedish Research Council for Health, Working Life and Welfare (Forte) for funding the project (2010-0142 and 2013-2012).

\section{Competing Interests Statement}

The authors declare that there is no conflict of interests regarding the publication of this paper.

\section{References}

Anthony, W. A. (1993). Recovery from mental illness: The guiding vision of the mental health service system in the 1990s. Psychiatric Rehabilitation Journal, 16(4), 11-23. http://dx.doi.org/10.1037/h0095655

Anthony, W. A., \& Mizock L. (2014). Evidence-Based Processes in an Era of Recovery: Im plications for Rehabilitation Counseling and Research. Rehabilitation Counseling Bulletin, 57(4), 219-227. http://dx.doi.org/10.1177/0034355213507979

Argentzell, E., Leufstadius, C., \& Eklund, M. (2014). Social interact ion among people with psychiatric disabilities - Does attending a day centre matter? International Journal of Social Psychiatry, 60(6), 519-527. http://dx.doi.org/10.1177/0020764013502318

Bejerholm, U., \& Eklund, M. (2004). Time-use and occupational performance among persons with schizophrenia. Occupational Therapy in Mental Health, 20(1), 27-47. http://dx.doi.org/10.1300/J004v20n01_02

Bejerholm, U., \& Lundgren-Nilsson, Å. (2015). Rasch Analysis of the Profiles of Occupational Engagement in people with Severe mental illness (POES) instrument. Health and Quality of Life Outcomes, 13(1), 1-8. http://dx.doi.org/10.1186/s12955-015-0327-0

Bellack, A. S. (2004) Skills Training for People with Severe Mental Illness. Psychiatric Rehabilitation Journal, 27(4), 375-91. http://dx.doi.org/10.2975/27.2004.375.391

Bengtsson-Tops, A., \& Hansson, L. (2001). Quantitative and qualitative aspects of the social network in schizophrenic patients living in the community. Relationship to sociodemographic characteristics and clinical factors and subjective quality of life. International Journal of Social Psychiatry, 47(3), 67-77. http://dx.doi.org/10.1177/002076400104700307

Berkman, L. F., \& Glass, T. (2000). Social integration, social networks, social support, and health. In L.F. Berkman \& I. Kawachi (Eds.), Social epidemiology (pp.137-173). New York: Oxford University Press. 
Bellamy, C. D., Garvin, C., MacFarlane, P., Mowbray, O. P., Mowbray, C. T., \& Holter, M. C. (2006). An analysis of groups in consumer-centered programs. American Journal of Psychiatric Rehabilitation, 9(3), 219-240. http://dx.doi.org/10.1080/15487760600962152

Biegel, D. E., Pernice-Duca, F., Chang, C-W., Chung, C-L., Min, M. O., \& D'Angelo, L. (2013). Family social networks and recovery from severe mental illness of Clubhouse members. Journal of Family Social Work, 16(4), 274-296. http://dx.doi.org/10.1080/10522158.2013.794379

Birren, J. E., Lubben, J. E., Rowe, J. C., \& Deutchman, D. E. (Eds.). (1991). The concept and measurement of quality of life in the frail elderly. Academic Press: San Diego.

Bonavigo, T., Sandhu, S., Pascolo-Fabrici, E., \& Priebe, S. (2016). What does dependency on community mental health services mean? A conceptual review with a systematic search. Social Psychiatry and Psychiatric Epidemiology, 1-14. http://dx.doi.org/10.1007/s00127-016-1180-0

Brunt D., \& Hansson, L. (2002). The social networks of persons with severe mental illness in in-patient settings and supported community settings. Journal of Mental Health, 11(6), 611-621. http://dx.doi.org/10.1080/09638230021000058175

Bryant, W., Craik, C., \& McKay, E. A.. (2005). Perspectives of day and accommodation services for people with enduring mental illness. Journal of Mental Health, 14(2), 109-120. http://dx.doi.org/10.1080/0963823050007360

Bryant, W., Vacher, G., Beresford, P., \& McKay, E.A. (2010). The modernisation of mental health day services: participatory action research exploring social networking. Mental Health Review Journal, 15(3), 11-21. http://dx.doi.org/10.5042/mhrj.2010.0655

Carolan, M., Onaga, E., Pernice-Duca, F., \& Jimenez, T. (2011). A place to be: The role of clubhouses in facilitating social support. Psychiatric Rehabilitation Journal., 35(2), 125-132. http://dx.doi.org/10.2975/35.2.2011.125.132

Catty, J., Burns, T., Comas, A., \& Poole, Z. (2008). Day centers for severe mental illness. Cochrane Database of Systematic Reviews, 3, 2008. http://dx.doi.org/10.1002/14651858.CD001710.pub2

Catty, J., Goddard, K, \& Burns, T. (2005a). Social services and health services day care in mental health: the social networks and care needs of their users. International Journal of Social Psychiatry, 51(1), 23-34. http://dx.doi.org/10.1177/002076400505326

Catty, J., Goddard, K., White, S., \& Burns, T. (2005b). Social networks among users of mental health day care--predictors of social contacts and confiding relationships. Social Psychiatry And Psychiatric Epidemiology, 40(6), 467-74. http://dx.doi.org/10.1007/s00127-005-0909-y

Coniglio, F., Hancock, N., \& Ellis, L. (2012). Peer Support within Clubhouse: A Grounded Theory Study. Community Mental Health Journal, 48(2), 153-160. http://dx.doi.org/10.1007/s10597-010-9358-5

Corrigan, P. W., \& Phelan, S. M. (2004). Social support and recovery in people with serious mental illnesses. Community Mental Health Journal, 40(6), 513-23. http://dx.doi.org/10.1007/s10597-004-6125-5

Davidson, L., Chinman, M., Sells, D., \& Rowe, M. (2006). Peer support among adults with serious mental illness: a report from the field. Schizophrenia Bulletin., 32(3), 443-450. http://dx.doi.org/10.1093/schbul/sbj043

Eklund, M., Bengtsson-Tops, A., \& Lindstedt, H. (2007). Construct and discriminant validity and dimensionality of the Interview Schedule for Social Interaction (ISSI) in three psychiatric samples. Nordic Journal of Psychiatry, 61(3), 182-188. http://dx.doi.org/10.1080/08039480701352439

Eklund, M., Gunnarsson, A. B., Sandlund, M., \& Leufstadius C. (2014). Effectiveness of an intervention to improve day centre services for people with psychiatric disabilities. Australian Occupational Therapy Journal, 61(4), 268-275. http://dx.doi.org/10.1111/1440-1630.12120

Eklund, M., \& Hansson L. (2007). Social network among people with persistent mental illness: associations with sociodemographic, clinical and health-related factors. International Journal of Social Psychiatry, 53(4), 293-305. http://dx.doi.org/10.1177/0020764006074540

Eklund, M., \& Markstrom, U. (2015). Outcomes of a Freedom of Choice Reform in Community Mental Health Day Center Services. Administration \& Policy in Mental Health \& Mental Health Services Research, 42(6), 664-671. http://dx.doi.org/10.1007/s10488-014-0601-1

Eklund, M., \& Sandlund, M. (2012). The life situation of people with persistent mental illness visiting day centers: 
A comparative study. Community Mental Health Journal, 48(5), 592-597. http://dx.doi.org/10.1007/s10597-011-9410-0

Elstad, T. A. (2014). Participation in a 'low threshold'community mental health service: an ethnographic study of social interaction, activities and meaning (Doctoral dissertation 1503-8181; 2014:95, Norwegian University of Science and Technology, Norway: NTNU-trykk). Retrieved from http://urn.kb.se/resolve?urn= urn:nbn:no:ntnu:diva-24723

Erickson, D. H., Beiser, M., \& Iacono, W. G. (1998). Social support predict 5-year outcome in 1st-episode schizophrenia. Journal of Abnormal Psychology, 107(4), 681-685. http://dx.doi.org/10.1037/0021-843X.107.4.681

Goldberg, R. W., Rollins, A. L., \& Lehman, A. F. (2003). Social network correlates among people with psychiatric disabilities. Psychiatric Rehabilitation Journal, 26(4), 393-402. http://dx.doi.org/10.2975/26.2003.393.402

Hardiman, E. R., \& Segal, S. P. (2003). Community membership and social networks in mental health self-help agencies. Psychiatric Rehabilitation Journal, 27(1), 25-33. http://dx.doi.org/10.2975/27.2003.25.33

Hawkley, L. C., \& Cacioppo, J. T. (2010). Loneliness matters: A theoretical and empirical review of consequences and mechanisms. Annals of Behavioral Medicine, 40(2), 218-27. http://dx.doi.org/10.1007/s12160-010-9210-8

Henderson, S., Duncan-Jones, P., Byrne, D. G., \& Scott, R. (1980). Measuring social relationships. The interview schedule for social interaction. Measuring social relationships the interview schedule for social interaction. Psychological medicine, 10(4), 723-734. http://dx.doi.org/10.1017/S003329170005501X

Hendryx, M., Green, C. A., \& Perrin, N. A. (2009). Social Support, Activities, and Recovery from Serious Mental Illness: STARS Study Findings. Journal of Behavioral Health Services \& Research, 36(3), 320-329. http://dx.doi.org/10.1007/s11414-008-9151-1

House, J. S. (1981). Work stress and social support. Reading, MA: Addison-Wesley.

Hultqvist, J., Markström, U., Tjörnstrand, C., \& Eklund, M. (2016). Programme characteristics and everyday occupations in day centres and clubhouses in Sweden. Scandinavian Journal of Occupational Therapy. 1-11. http://dx.doi.org/10.1080/11038128.2016.1200669

Kawachi, I., \& Berkman, L. F. (2001). Social ties and mental health. Journal of Urban Health, 78(3), 458-467. http://dx.doi.org/10.1093/jurban/78.3.458

McKay, C., Nugent, K. L., Johnsen, M., Eaton, W. W., \& Lidz, C. W. (2016). A Systematic Review of Evidence for the Clubhouse Model of Psychosocial Rehabilitation. Administration and Policy in Mental Health and Mental Health Services Research, 1-20. http://dx.doi.org/10.1007/s10488-016-0760-3

Mowbray, C. T., Woodward , A. T., Holter, M. C., MacFarlane, P., \& Bybee D. (2009). Characteristics of Users of Consumer-Run Drop-In Centers Versus Clubhouses. Journal of Behavioral Health Services \& Research, 36(3), 361-71. http://dx.doi.org/10.1007/s11414-008-9112-8

Nilsson, I., Argentzell, E., Sandlund, M., Leufstadius, C., \& Eklund, M. (2011). Measuring perceived meaningfulness in day centres for persons with mental illness. Scandinavian Journal of Occupational Therapy, 18(4), 312-320. http://dx.doi.org/10.3109/11038128.2010.522592

Noordsy, D., Torrey, W., Mueser, K., Mead, S., O'Keefe, C., \& Fox, L. (2002). Recovery from severe mental illness: an intrapersonal and functional outcome definition. International Review of Psychiatry, 14(4), 318-26. http://dx.doi.org/10.1080/0954026021000016969

Norman, C. (2006). The Fountain House movement, an alternative rehabilitation model for people with mental health problems, members' descriptions of what works. Scandinavian Journal of Caring Sciences, 20(2), 184-192. http://dx.doi.org/10.1111/j.1471-6712.2006.00398.x

Oliver, J., Huxley, P., Priebe, S., \& Kaiser, W. (1997). Measuring the quality of life of severely mentally ill people using the Lancashire Quality of Life Profile. Social Psychiatry and Psychiatric Epidemiology, 32(2), 76-83. http://dx.doi.org/10.1007/BF00788924

Onken, S. J., Craig, C. M., Ridgway, P., Ralph, R. O., \& Cook, J. A. (2007). An analysis of the definitions and elements of recovery: a review of the literature. Psychiatric Rehabilitation Journal, 31(1), 9-22. http://dx.doi.org/10.2975/31.1.2007.9.22

Pernice-Duca, F., \& Onaga, E. (2009). Examining the contribution of social network support to the recovery 
process among clubhouse members. American Journal of Psychiatric Rehabilitation, 12(1), 1-30. http://dx.doi.org/10.1080/15487760802615566

Pernice-Duca, F. (2008). The structure and quality of social network support among mental health consumers of

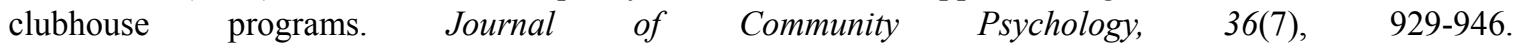
http://dx.doi.org/10.1002/jcop.20265

Psykiatrisamordningen. (2006). Välfärd och valfrihet:service, stöd och vård för psykiskt störda: slutbetänkande [Welfare and freedom of choice: service, support and care for the mentally ill : final report].

Raeburn, T., Halcomb, E., Walter, G., \& Cleary M. (2013). An overview of the clubhouse model of psychiatric rehabilitation. Australasian Psychiatry, 21(4), 376-378. http://dx.doi.org/10.1177/1039856213492235

Raeburn, T., Schmied, V., Hungerford, C., \& Cleary, M. (2016). The use of social environment in a psychosocial clubhouse to facilitate recovery-oriented practice. British Journal of Psychiatry Open, 2(2), 173-178. http://dx.doi.org/10.1192/bjpo.bp.115.002642

Rosenberg, M. (1965). Society and the adolescent self-image. Princeton, N.J.: Princeton University Press. http://dx.doi.org/10.1515/9781400876136

Sinclair, S. J., Blais, M. A., Gansler, D. A., Sandberg, E., Bistis, K., \& LoCicero, A. (2010). Psychometric Properties of the Rosenberg Self-Esteem Scale: Overall and Across Demographic Groups Living Within the United States. Evaluation \& the Health Professions, 33(1), 56-80. http://dx.doi.org/10.1177/016327870935618

Startup, M., Jackson, M. C., \& Bendix, S. (2002). The concurrent validity of the Global Assessment of Functioning (GAF). British Journal of Clinical Psychology, 41(4), 417-422. http://dx.doi.org/10.1016/j.comppsych.2011.04.007

Stein, L., Barry, K., Dien, G., Hollingsworth, E., \& Sweeney, J. K. (1999). Work and Social Support: A Comparison of Consumers Who Have Achieved Stability in ACT and Clubhouse Programs. Community Mental Health Journal, 35(2), 193-204. http://dx.doi.org/10.1023/A:1018780916794

Sveriges Fontänhus Riksförbund [The Swedish Clubhouse Federation] (2016, september 2016). Retrived September 29, 2016 from, http://www.sverigesfontanhus.se/.

Sweeney, A., Davies, J., McLaren, S., Whittock, M., Lemma, F., Belling, R., et al. (2016). Defining continuity of care from the perspectives of mental health service users and professionals: an exploratory, comparative study. Health Expectations, 19(4), 973-98. http://dx.doi.org/10.1111/hex.12435

Sörgaard, K.W., Hansson, L., Heikkilä, J., Vinding, H.R., Bjarnason, O., Bengtsson-Tops, A., et al. (2001). Predictors of social relations in persons with schizophrenia living in the community: A Nordic multicentre $\begin{array}{lllll}\text { study. Social Psychiatry \& Psychiatric Epidemiology, } & 36(1), & 13-19 .\end{array}$ http://dx.doi.org/10.1007/s001270050285

Tanaka, K., Craig, T., \& Davidson, L. (2015). Clubhouse Community Support for Life: Staff-Member Relationships and Recovery. Journal of Psychosocial Rehabilitation and Mental Health, 2(2), 131-41. http://dx.doi.org/10.1007/s40737-015-0038-1

Tjörnstrand, C., Bejerholm, U., \& Eklund, M. (2011) Participation in day centres for people with psychiatric disabilities: characteristics of occupations. Scandinavian Journal of Occupational Therapy, 18(4), 243-253. http://dx.doi.org/10.3109/11038128.2011.583938

Tjörnstrand, C., Bejerholm, U., \& Eklund, M. (2013a). Participation in day centres for people with psychiatric disabilities - A focus on occupational engagement. British Journal of Occupational Therapy, 73, 144-150. http://dx.doi.org/10.4276/030802213X13627524435225

Tjörnstrand, C., Bejerholm, U., \& Eklund, M. (2013b). Psychometric testing of a self-report measure of engagement in productive occupations. Canadian Journal of Occupational Therapy, 80(2), 101-110. http://dx.doi.org/10.1177/0008417413481956

Topor, A., Borg, M., Di Girolamo, S., \& Davidson, L. (2011) Not just an individual journey: Social aspects of $\begin{array}{lllll}\text { recovery. International Journal of Social Psychiatry, } & \text { 57(1), }\end{array}$ http://dx.doi.org/10.1177/0020764009345062

Torrey, W. C., Mueser, K. T., McHugo, G. H., \& Drake, R. E. (2000). Self-esteem as an outcome measure in studies of vocational rehabilitation for adults with severe mental illness. Psychiatric Services, 51(2), 229-288. 
http://dx.doi.org/10.1176/appi.ps.51.2.229

Townley, G., Miller, H., \& Kloos, B. (2013). A little goes a long way: The impact of distal social support on community integration and recovery of individuals with psychiatric disabilities. American Journal of Community Psychology, 52(1-2):84-96. http://dx.doi.org/10.1007/s10464-013-9578-2

Tracy, E.M., \& Biegel, D.E. (2006). Personal social networks and dual disorders: A literature review and implications for practice and future research. Journal of Dual Diagnosis, 2(2), 59-88. http://dx.doi.org/10.1300/J374v02n0204

Wasserman, .S \& Faust, K. (1994). Social network analysis. Methods and applications. New York, NY: Cambridge University Press. http://dx.doi.org/10.1017/CBO9780511815478

Vatnaland, T., Vatnaland, J., Friis, S., \&, Opjordsmoen, S. (2007). Are GAF scores reliable in routine clinical use? Acta Psychiatrica Scandinavica, 15(4), 326-330. http://dx.doi.org/10.1111/j.1600-0447.2006.00925.x

Yurkovich, E., Smyer, T., \& Dean, L. (1999). Maintaining health: Proactive client-oriented community day treatment centres for the chronic mentally ill. Journal of Psychiatric and Mental Health Nursing, 6, 61-69. http://dx.doi.org/10.1046/j.1365-2850.1999.00186.x

\section{Copyrights}

Copyright for this article is retained by the author(s), with first publication rights granted to the journal.

This is an open-access article distributed under the terms and conditions of the Creative Commons Attribution license (http://creativecommons.org/licenses/by/4.0/). 